\title{
Recommended dietary reference intakes, nutritional goals and dietary guidelines for fat and fatty acids: a systematic review
}

\author{
Javier Aranceta ${ }^{1,2 *}$ and Carmen Pérez-Rodrigo ${ }^{2}$ \\ ${ }^{1}$ Department of Preventive Medicine and Public Health, University of Navarra, Pamplona, Spain \\ ${ }^{2}$ Community Nutrition Unit, Bilbao Department of Public Health, Ugalde 7, 48012 Bilbao, Spain
}

\begin{abstract}
Dietary fat and its effects on health and disease has attracted interest for research and Public Health. Since the 1980s many bodies and organizations have published recommendations regarding fat intake. In this paper different sets of recommendations are analyzed following a systematic review process to examine dietary reference intakes, nutritional goals and dietary guidelines for fat and fatty acids. A literature search was conducted in relevant literature databases along a search for suitable grey literature reports. Documents were included if they reported information on either recommended intake levels or dietary reference values or nutritional objectives or dietary guidelines regarding fat and/or fatty acids and/or cholesterol intake or if reported background information on the process followed to produce the recommendations. There is no standard approach for deriving nutrient recommendations. Recommendations vary between countries regarding the levels of intake advised, the process followed to set the recommendations. Recommendations on fat intake share similar figures regarding total fat intake, saturated fats and trans fats. Many sets do not include a recommendation about cholesterol intake. Most recent documents provide advice regarding specific $n-3$ fatty acids. Despite efforts to develop evidence based nutrient recommendations and dietary guidelines that may contribute to enhance health, there are still many gaps in research. It would be desirable that all bodies concerned remain transparent about the development of dietary recommendations. In order to achieve this, the type of evidence selected to base the recommendations should be specified and ranked. Regular updates of such recommendations should be planned.
\end{abstract}

Key words: Fat: Fatty acids: Omega-3: Dietary recommendations

Fat is an important source of energy, facilitates the absorption of fat-soluble dietary components such as vitamins. Additionally, fats and oils are important sources of essential fatty acids (EFA). Most unsaturated fatty acids in the diet have the cis configuration, but trans fatty acids (TFA) are present as well. Fats also play an important role by enhancing the taste and acceptability of foods and fat components contribute to the texture, flavour and aroma of foods.

The approach to establish nutrient recommendations has changed over time. While the early sets of recommendations focused on ensuring adequate intakes of nutrients from foods to prevent deficiencies, a shift from this paradigm emerged in the middle of the 20th century.

Atwater published the USDA first dietary standards in 1894 and in 1916 the first USDA Food guide. In the UK an early report including dietary recommendations was published in 1938 by the Technical Commission on Nutrition of the League of Nations ${ }^{(1)}$.

Better socioeconomic, living and nutrition conditions for wider proportions of the population in many countries led to the epidemiological transition. Prevalence of cardiovascular diseases as well as mortality rates for this cause and also for cancer progressively increased, while death rates due to infectious diseases decreased.

The interest in dietary fat and its effects, especially with regard to its role in cardiovascular disease was stimulated by several papers published in the early 1950s. In the 70s, evidence from the Seven Countries' study conducted by Ancel Keys and colleagues found a significant association between fat and saturated fat intake and heart disease mortality. Despite methodological limitations, the growing evidence linking diet and chronic diseases brought a new approach to dietary recommendations, aimed not only to prevent deficiencies, but also to encourage dietary changes in order to prevent chronic diseases ${ }^{(1)}$.

The first guidelines issued by the American Heart Association in 1957 already cited 'Diet may play an important role in the pathogenesis of atherosclerosis'. In 1977, the Senate Select Committee on Nutrition and Human Needs published the report Dietary Goals for the United States. Three years later followed Dietary Guidelines for Americans ${ }^{(2)}$.

In 1991 a document published in the UK introduced a new concept: Dietary Reference Values (DRVs) ${ }^{(3)}$. In 1994 the Food and Nutrition Board of the Institute of Medicine (IOM) 
published the dietary reference intakes (DRIs) for the United States of America and Canada including many aspects of the conceptual framework from the report published in the United Kingdom $^{(4)}$. These DRIs represented a new conceptual framework in the way nutrient recommendations are established and used. Besides the prevention of deficiencies, DRIs were intended to help individuals optimize their health, prevent disease, and avoid consuming too much of a nutrient. The DRIs included four nutrient-based reference values: estimated average requirement (EAR), the recommended dietary allowance (RDA), the adequate intake (AI) and the tolerable upper intake level (UL). The EAR is defined as the average daily nutrient intake level that is estimated to meet the requirements of half of the healthy individuals in a particular life stage and gender group. The RDA represents the average daily dietary nutrient intake level that is sufficient to meet the nutrient requirements of nearly all (97-98\%) healthy individuals in a particular life stage and gender group. When an RDA cannot be determined, an AI is estimated which is the recommended average daily intake level based on observed or experimentally determined approximations or estimates of nutrient intake by a group (or groups) of apparently healthy people that are assumed to be adequate.

The Acceptable Macronutrient Distribution Ranges (AMDR) was introduced by the IOM in the 2002 report on energy and macronutrients ${ }^{(5)}$. An AMDR is defined as a range of intakes for a particular energy source that is associated with reduced risk of chronic diseases while providing adequate intakes of essential nutrients. It is expressed as a percentage of total energy intake and has a lower and upper limit, determined mainly by the lowest or highest value judged to have an expected impact on health.

In 1978 and in 1994 expert groups convened by FAO/WHO published technical reports on dietary fats and health, including dietary recommendations ${ }^{(6)}$. The expert group preparing the technical report on nutrition and the prevention of chronic diseases in 2002-2003 considered fat intake and fat quality as well $^{(7)}$. Dietary trends show that over the past decades, in line with the recommended dietary changes, fat consumption has decreased in many countries. However, the expected health outcomes have not paralleled the change and new problems emerged. Controversies raised by new evidence contribute to the debate with regards to total fat intake and fatty acids, and motivated an update to the FAO/WHO report in $2008^{(8)}$. When preparing this report, the strength of the existing evidence for developing dietary guidelines was considered. The evidence was classified as convincing, probable, possible, and insufficient, according to directions in a background document prepared $^{(9)}$.

Many countries, or even different bodies and organizations within the same country, have formulated nutrient recommendations and dietary guidelines. However, different approaches have been used. The process followed, criteria used or the type of evidence are not always clearly specified.

To address this issue, we conducted a systematic review of the literature examining dietary reference intakes, nutritional goals and dietary guidelines for fat and fatty acids for healthy individuals to achieve optimal health and the approaches used to formulate them.

\section{Methods}

\section{Search strategy and selection}

We searched the following electronic literature databases: Medlars Online International Literature (MEDLINE) via PubMed (1966-present), EMBASE (1980-present), SCOPUS, OVID, Web of Knowledge, Institute for Scientific Information (ISI) (1981-present), The Cochrane Library Plus, International Pharmaceutical Abstracts (IPA), Psychology Information (PsycINFO) (1971-present), Cumulative Index to Nursing and Allied Health Literature (CINAHL) (1981-present), Biological Abstracts, Food Science and Technology Abstracts (FSTA) (1969-present), Latin American and Caribbean Heath Sciences Literature (LILACS) (1982-present), Pan American Health Organization Library (PAHO) and World Health Organization Library Information System (WHOLIS). The last search was run on 10 April 2011. We also searched for relevant grey literature reports and documents following a snowball process and expert informants.

The key words and search equation used were as follows: ((( ('Dietary Fats/administration and dosage'(Majr) OR 'Dietary Fats/adverse effects'(Majr)) OR ('Fatty Acids, Omega-3/administration and dosage'(Mesh) OR 'Fatty Acids, Omega-3/ adverse effects'(Mesh))) OR ('Fatty Acids, Omega-6/administration and dosage'(Mesh) OR 'Fatty Acids, Omega-6/adverse effects'(Mesh))) OR ('Trans Fatty Acids/administration and dosage'(Mesh) OR 'Trans Fatty Acids/adverse effects'(Mesh))) AND 'Nutrition Policy'(Majr) AND ('humans'(MeSH Terms) AND (English(lang) OR French(lang) OR German(lang) OR Italian(lang) OR Spanish(lang) OR Portuguese(lang))).

For this review we considered documents written either in English, French, German, Italian, Spanish, or Portuguese. Documents were included if they reported information on either recommended intake levels or dietary reference values or nutritional objectives or dietary guidelines regarding fat and/or fatty acids and/or cholesterol intake or if reported background information on the process followed to produce the recommendations. The reference values referred to healthy population or specific age and gender healthy population groups. When a series of dietary recommendations were updated at different points in time, we considered the most updated documents.

Following this process, 304 documents and reports were retrieved and screened by title and abstract, including 11 reports from grey literature. After the first screening process, 102 duplicated references plus 38 non relevant documents were excluded, thus yielding 164 potentially relevant documents and reports which were retrieved full text and analyzed in detail. According to the PRISMA statement ${ }^{(10)}$, we also scanned reference lists of articles retrieved full text. After reading full text, 18 more references were identified, searched and added. Some 72 documents satisfied the inclusion criteria and were considered for this review (Fig. 1). Methods of the search and inclusion criteria were specified in advance and 


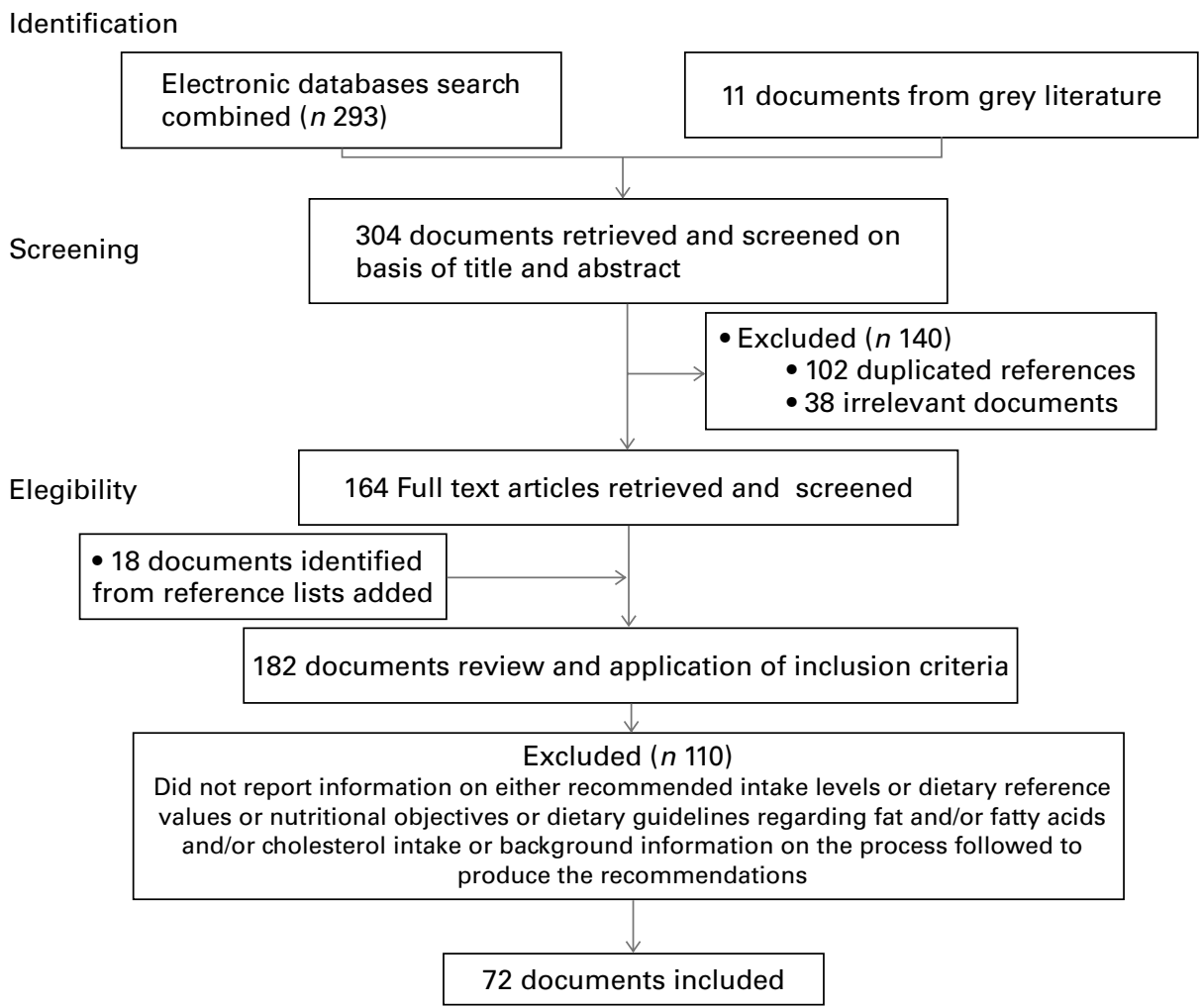

Fig. 1. Flow diagram of study identification, screening and selection for the systematic review.

documented in a protocol. Two independent reviewers screened the references retrieved and analyzed the documents for inclusion using EndNote and Systematic Reviews Collaborative Tool (SysCollab) ${ }^{(11)}$, a software tool specifically designed to be used in this series of systematic reviews on omega-3.

The following data were extracted from the selected documents: recommended intakes (type of Dietary Reference Intake (DRI) and amount) for total fat, saturated fatty acids (SFA); monounsaturated fatty acids (MUFA); polyunsaturated fatty acids (PUFA); trans fatty acids; linoleic acid (LA); n3 FA; eicosapentaenoic acid (EPA); docosahexaenoic acid (DHA); EPA + DHA; alpha-linolenic acid (ALA); n6:n3 ratio; cholesterol; year of publication; country and/or institution responsible; reported criteria and evidence used to establish the recommendations. Data extraction forms were documented on a protocol.

\section{Recommended intakes for total fat and fatty acids}

A number of papers reported information related to recommendations issued by the same organization. The documents retrieved that met the inclusion criteria have been produced by international organizations with a worldwide scope, such as expert committees convened by the Food and Agriculture Organization of the United Nations (FAO) and the World Health Organization $(\mathrm{WHO})^{(8)}$, the International Society for the Study of Fatty Acids and Lipids ${ }^{(9,12)}$ or the World Association of Perinatal Medicine, Early Nutrition Academy and Child Health Foundation ${ }^{(13)}$. Other reports were produced by American organizations and institutions, such as the American Heart Association ${ }^{(14,15)}$; American Academy of Pediatrics ${ }^{(16,17)}$; the United States Department of Agriculture (USDA) $)^{(18)}$ or the Institutes of Medicine (IOM) of the National Academies of Science ${ }^{(5)}$; European organizations and agencies, such as the European Agency for Food Safety $(\text { EFSA })^{(19)}$ or the European Society of Cardiology ${ }^{(20)}$ or reports produced by organizations from different European, Asian and Pacific countries. The oldest document was produced in 1991, while several documents were issued in 2010.

A number of countries have published their own recommended intakes and guidelines or have adopted those suggested either by international organizations or by other countries. There are disparities across countries in current dietary reference values and recommendations for total fat and fatty acids. So far, no standardized methodology to define these values has been adopted, although some initiatives have suggested methodological approaches, such as Eurreca, an EU funded Network of Excellence aimed to harmonize dietary reference values for micronutrients across Europe $^{(21,22)}$. Despite total fat and fatty acids was not the main focus of Eurreca, the tools, products and processes developed during the project can also be useful to harmonize and update recommended intakes for fats. It is also worth mentioning the framework for DRI Development produced as a background paper by Taylor in 2008 for the $\mathrm{IOM}^{(23)}$ and the background document prepared for the FAO/WHO expert group $2008^{(9)}$

The reports and documents included in this review were produced at varying points in time, thus considering the different evidence available at the time. Additionally, different 
types of evidence, endpoints or even diverse assumptions may have been considered to establish the recommended values. In the documents reviewed the background information on the formulation process often is not sufficient to clarify these aspects.

\section{Criteria used to establish recommendations}

The types of criteria and types of evidence used to set specific guidelines was not always clearly specified in the reports. The aims used to define dietary requirements included to prevent clinical deficiencies; to provide optimal health or to reduce the risk of developing chronic disease.

Examples of chronic disease outcomes used as criterion for dietary recommendations for fatty acids include coronary heart disease (CHD), obesity, diabetes, and specific types of cancers. Examples of physiological measures used as criterion to set dietary recommendations for dietary fatty acids are serum cholesterol levels, triglyceride levels, and neural integrity. Deficiency symptoms are most often studied in the case series, animal experiments, or short-term controlled feeding studies.

When insufficient data are available on disease or physiological criteria for setting recommendations, average intakes in national surveys are used. That is the case for some fatty acids and age groups. However, such intakes may not be optimal for reducing disease risk.

Equilibrium maintenance describes the balance of nutrient intake and loss, as measured by factorial estimation, which involves estimating the determinant factors for the requirement, such as increased requirements for growth, pregnancy, and lactation, or losses via the urine or feces ${ }^{(23,24)}$.

\section{Type and level of evidence used}

Some reports specify the outcomes and related supportive evidence, although the kind and level of evidence is missing (ecological studies, prevalence studies; retrospective casecontrol studies of disease outcomes; randomized controlled trials (RCTs) of physiological measures; prospective cohort studies of disease outcomes; RCTs of disease outcomes).

\section{$D R / s$ used}

EAR and RDA have not been traditionally used for fats and fatty acids. UL has been used for total fat, saturated fat, total polyunsaturated fat, ALA, EPA + DHA, and dietary cholesterol. AI has been used for total fat, LA, ALA, and EPA + DHA. Acceptable macronutrient distribution range (AMDR) has been used for total fat, LA, and ALA. However, some reports do not specify the DRI value used.

The framework for the DRI development background paper suggests that even if there is limited data, scientific judgment can be important. Nevertheless, it must be noted that reliance on scientific judgment in the absence of optimal data, can be misleading and result in even harmful health consequences $^{(23)}$.

\section{Dietary recommended intakes}

\section{Total fat}

Table 1 shows recommendations for total fat, SFA, TFA, cholesterol, MUFA and PUFA for adults in the different sets compared $^{(5,7,8,12-15,18,19,25-38)}$ and Table 2 shows recommendations for infants and children. In most documents the recommended intake for total fats in adults is $20-35 \% \mathrm{E}$, although the lower recommended value is $15 \%$ in Asian countries (Oman, India, Korea), and also in the FAO/WHO report $2008^{(8)}$. In some sets the upper level is up to $40 \%$ for people with optimal body weight. Higher levels of total fat intake are recommended for infants $0-6$ mo., $40-60 \% \mathrm{E}$. The FAO/WHO $2008^{(8)}$; IOM $^{(5)}$ and $\mathrm{EFSA}^{(19)}$ reports use AMDR for total fat for adults and children.

To set these values the documents refer to evidence in relation to total fat intake and obesity, weight gain, coronary heart disease (CHD) and cancer. Most recent documents report on the insufficient evidence for the association between total fat intake and body weight and probable evidence that increased SFA intake results in increased weight ${ }^{(39-42)}$; no association between total fat intake and cancer $^{(43)}$; no clear benefits of a low fat high carbohydrate diet in relation to blood lipids, glucose or blood pressure ${ }^{(44,45)}$. Evidence from cohort studies reported conflicting results on total fat intake and the positive association with type 2 diabetes ${ }^{(46)}$.

Low fat diets $<20 \%$ E reduce LDL-cholesterol but also HDLcholesterol, increase triglycerides (TGC) and can increase the risk of inadequate intakes of essential fatty acids and fatsoluble vitamins. Some reports highlight that the lower limit of fat intake for adults is difficult to define because there is limited evidence ${ }^{(5,6,18)}$.

The FAO/WHO 2008 recommendations for total fat for infants slightly decrease in the lower and upper values of the acceptable range compared to previous reports. This change is based on the need to control energy intake to prevent the progression of the obesity epidemic, in light of the physiologic standards for energy intake and the acceptable weight for children $0-5$ years according to the new WHO growth reference standards ${ }^{(8)}$.

\section{SFA}

Most documents include a recommended intake for SFA below $10 \% \mathrm{E}$. The American Heart Association recommends an SFA intake below $7 \% \mathrm{E}^{(14)}$. In some cases reports advise either to limit intake or to keep intake of SFA as low as possible. The same value is reported for infants and children, except in the Dutch recommendations which set this limit up to $15 \%$ for infants up to 12 months. An upper AMRD is reported for adults and children in the FAO/WHO 2008 report.

To set this value, reports refer to convincing evidence, about LDL-cholesterol and risk of cardiovascular disease ${ }^{(47-54)}$. Most recent evidence shows a positive effect when SFA are reduced by replacing with PUFA, fruit and vegetables ${ }^{(55,56)}$, but not when replaced by easily digested carbohydrates ${ }^{(57)}$. Replacement of SFA with carbohydrates may have little benefit. In line with this, the Dietary Guidelines for Americans 2010 
Table 1. Recommendations for fat and fatty acid intakes ${ }^{\mathrm{a}}$ for adults according to different bodies

\begin{tabular}{|c|c|c|c|c|c|c|c|}
\hline Region $^{\mathrm{b}}$ & Organization/Country & Total fat & SFA & Trans & Cholesterol & MUFA & PUFA \\
\hline \multirow[t]{2}{*}{ International } & $\mathrm{FAO} / \mathrm{WHO}, 2008^{(8)}$ & $20-35 \% E$ & $10 \% \mathrm{E}$ & & & $\begin{array}{l}{ }^{\circ} \text { By difference, }{ }^{d} \text { up to } \\
15-20 \% \mathrm{E}, \\
\text { according to total fat } \\
\text { intake }\end{array}$ & $6-11 \% \mathrm{E}$ \\
\hline & $\begin{array}{l}\text { WHO, 2003 } \\
\text { ISSFAL, } 1999-2004^{(12)}\end{array}$ & $15-30 \% \mathrm{E}$ & $<10 \% \mathrm{E}$ & $<1 \% \mathrm{E}$ & $<300 \mathrm{mg} /$ day & & $6-10 \% E$ \\
\hline \multirow[t]{5}{*}{ North America } & AHA 2006; $2009^{(14,15)}$ & $25-35 \% \mathrm{E}$ & $<7 \% \mathrm{E}$ & $<1 \% \mathrm{E}$ & & & $\begin{array}{l}5-10 \% \text { E Healthy } \\
\text { eating patterns }\end{array}$ \\
\hline & IOM 2002/2005(5) & $20-35 \% \mathrm{E}$ & As low as possible & As low as possible & & & $\begin{array}{l}\text { Al: } 17 \mathrm{~g} / \mathrm{d} \mathrm{M} ; 12 \mathrm{~g} / \mathrm{d} \mathrm{F} \\
(5-6 \% \mathrm{E})\end{array}$ \\
\hline & ADA USA \& Canada, $2007^{(25)}$ & $20-35 \% \mathrm{E}$ & $<10 \% \mathrm{E}$ & & & & \\
\hline & $\begin{array}{l}\text { USDA Dietary Guidelines for } \\
\text { Americans, 2010 }\end{array}$ & & $\begin{array}{l}<10 \% \mathrm{E} \text { (by replacing them } \\
\text { with monounsaturated and } \\
\text { polyunsaturated fatty } \\
\text { acids) }\end{array}$ & $\begin{array}{l}\text { Avoid consumption of } \\
\text { trans-fats from industrial } \\
\text { sources and limit to }<0.5 \% \\
\text { E from natural sources }\end{array}$ & $\begin{array}{l}<300 \mathrm{mg} / \text { day; }<200 \mathrm{mg} / \text { day } \\
\text { for individuals with or at } \\
\text { high risk for CVD and } \\
\text { Type } 2 \text { diabetes. }\end{array}$ & & \\
\hline & $\begin{array}{l}\text { American Diabetes Association, } \\
2008^{(26)}\end{array}$ & $30 \% \mathrm{E}$ & $<7 \% \mathrm{E}$ & minimized & $<200 \mathrm{mg} / \mathrm{day}$ & & \\
\hline \multirow[t]{9}{*}{ Europe } & EURODIET, $2000^{(27)}$ & $20-30 \% \mathrm{E}$ & $<10 \% \mathrm{E}$ & $<2 \% \mathrm{E}$ & & & \\
\hline & $\begin{array}{l}\text { EFSA, } 2010^{(19)} \\
\text { Fourth Joint Task Force of the } \\
\text { European Society of Cardiology, } \\
2007^{(20)}\end{array}$ & $\begin{array}{l}20-35 \% \mathrm{E} \\
<30 \% \mathrm{E}\end{array}$ & $\begin{array}{l}\text { As low as possible } \\
10 \% \mathrm{E}\end{array}$ & As low as possible & & & \\
\hline & D.A.C.H., $2000^{(28)}$ & $30 \% \mathrm{E}$ & $<10 \% \mathrm{E}$ & $<1 \% \mathrm{E}$ & $<300 \mathrm{mg} /$ day & & $7-10 \% \mathrm{E}$ \\
\hline & $\begin{array}{l}\text { UK Committee on Nutrition (COMA, } \\
\text { 1991) }\end{array}$ & $35 \% \mathrm{E}$ & $10 \% \mathrm{E}$ & $2 \% \mathrm{E}$ & & $12 \% \mathrm{E}$ & $6 \% \mathrm{E}$ \\
\hline & $\begin{array}{l}\text { Dutch Health Council, } 2001- \\
2006^{(29,30)}\end{array}$ & $20-40 \% \mathrm{E}$ & $<10 \% \mathrm{E}$ & $<\% 1 \mathrm{E}$ & & $\begin{array}{l}\text { (MUFA + PUFA: } \\
8-28 \% \text { E) }\end{array}$ & $12 \% \mathrm{E}$ \\
\hline & $\begin{array}{l}\text { AFFSA, CNERNA \& CNRS. France, } \\
2001-2005^{(31)}\end{array}$ & $30-35 \% \mathrm{E}$ & $<8 \% \mathrm{E}$ & $<2 \% \mathrm{E}$ & & $20 \% \mathrm{E}$ & \\
\hline & $\begin{array}{l}\text { Conseil Supérieur de la Santé. } \\
\text { Belgium, } 2009^{(32)}\end{array}$ & $30-35 \% \mathrm{E}$ & $<10 \% \mathrm{E}$ & $<1 \% \mathrm{E}$ & $<300 \mathrm{mg} / \mathrm{day}$ & $>10 \% \mathrm{E}$ & $5,3-10,0 \% \mathrm{E}$ \\
\hline & $\begin{array}{l}\text { Nordic Nutrition Recommendations } \\
2004^{(33)}\end{array}$ & $25-35 \% \mathrm{E}$ & $<10 \%$ & & & $10-15 \% \mathrm{E}$ & $5-10 \% \mathrm{E}$ \\
\hline & SENC. Spain, $2011^{(34)}$ & $\leq 35 \% \mathrm{E}$ & $\leq 10 \% \mathrm{E}$ & $<1 \% \mathrm{E}$ & $\begin{array}{l}<350 \mathrm{mg} / \mathrm{d}<110 \mathrm{mg} / 1000 \\
\text { kcal }\end{array}$ & $20 \% \mathrm{E}$ & $5 \% \mathrm{E}$ \\
\hline \multirow[t]{4}{*}{ Asia-Pacific } & $\begin{array}{l}\text { NHRC. Australia \& New Zealand, } \\
2006^{(35)}\end{array}$ & $30 \% \mathrm{E}$ & $10 \% \mathrm{E}$ & & & & $6-8 \% \mathrm{E}$ \\
\hline & KHIDI/MOHW. Korea, 2008 ${ }^{(36)}$ & $<20 \% \mathrm{E}$ & & & & & \\
\hline & $\begin{array}{l}\text { National Institute of Nutrition. India, } \\
2009^{(37)}\end{array}$ & $>20 \% \mathrm{E}$ & Limit & Minimize & & & \\
\hline & $\begin{array}{l}\text { Department of Nutrition, Ministry of } \\
\text { Health Oman. Oman, } 2009^{(38)}\end{array}$ & $15-30 \% \mathrm{E}$ & $<10 \% \mathrm{E}$ & $<1 \% \mathrm{E}$ & & By difference ${ }^{c}$ & $6-10 \% \mathrm{E}$ \\
\hline
\end{tabular}

SFA: Saturated Fatty Acids; Trans: Trans Fatty Acids; MUFA: Monounsaturated Fatty Acids; PUFA: Polyunsaturated Fatty Acids \%E: \% Energy intake. M: males; F: Females; Al: Adequate Intake. a Recommendations for total fat, saturated fat (SFA), trans fatty acids (Trans), monounsaturated fats (MUFA) and polyunsaturated fats (PUFA) are expressed as percent energy intake. Region: Continent or region where recommendations apply.

dCan amount up to $15-20 \% \mathrm{E}$.

${ }^{e}$ The AHA supports an omega- 6 PUFA intake of at least $5 \%$ to $10 \%$ of energy in the context of other AHA lifestyle and dietary recommendations. 


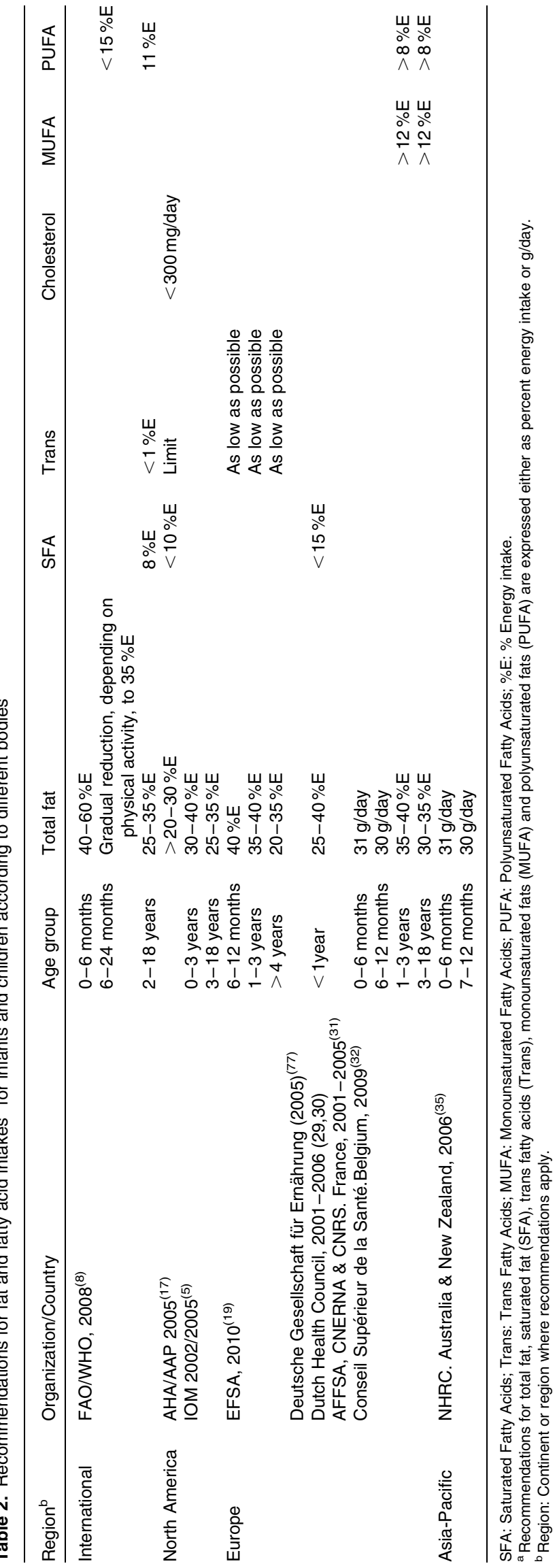

recommend SFA intake $<10 \%$ by replacing them with monounsaturated and polyunsaturated fatty acids.

It is noted that individual SFA lauric (C12:0), myristic (C14:0), palmitic acids (C16:0), and stearic acid (C18:0) have different effects on plasma cholesterol levels.

\section{MUFA}

The majority of the documents included in this review do not set a recommended intake for MUFA. The FAO/WHO 2008 report $^{(8)}$ does not include a recommended level but states that an AMDR for MUFA intake should be calculated by difference, subtracting from total fat intake levels those for SFAs, PUFAs and trans fatty acids. In Spain, a country with high olive oil consumption, MUFA intake can account up to $20 \% \mathrm{E}^{(34)}$.

Evidence reported to support the recommendations refer to the potential benefits of MUFA intake on blood lipid profile and CVD risk factors. There is convincing evidence that substituting carbohydrates with MUFAs raises HDL-cholesterol levels; possible evidence that substituting carbohydrates with MUFAs improves insulin sensitivity; convincing evidence that substituting SFAs with MUFAs lowers LDL-cholesterol levels and the TC/HDL-cholesterol ratio ${ }^{(48,56,58)}$.

It is unclear whether sufficient new evidence exists to reevaluate the lack of specific dietary recommendations for monounsaturated fat intake.

\section{PUFA}

Many reports do not include a value for all PUFAs, but specify recommended intake values for $n$-3 PUFAs and for $n$-6-PUFAs. For those reports including a value for PUFAs, there are discrepancies in the recommended intake levels. While some reports recommend intakes between $6-10 \% \mathrm{E}$ for PUFAS, other sets of recommendations consider lower values, 6$6.5 \% \mathrm{E}$. For infants between 6-12 mo., an upper AMRD of $15 \%$ is included in the FAO/WHO 2008 report, $11 \%$ for children aged 2-18 yr.

PUFAs include $n-6$ and $n$ - 3 fatty acids. Linoleic acid (LA), an $n-6$ fatty acid, and alfa-linolenic acid (ALA), an n-3 fatty acid, are both essential fatty acids that cannot be synthesized by humans and must be supplied with the diet. The minimum intake levels for essential fatty acids are $2.5 \% \mathrm{E}$ LA plus $0.5 \%$ E ALA to prevent deficiency symptoms in adults ${ }^{(5,8)}$.

Evidence considered to establish these recommendations is related to the favourable effects of LA on blood lipid profile, and its association with a lower risk of CHD events and reduced risk of type 2 diabetes ${ }^{(59)}$. Although clinical benefits have not been observed across all studies, several new experimental and prospective observational studies support that ALA consumption reduces the incidence of $\mathrm{CHD}^{(60)}$. Consumption of $n$-3 PUFAs eicosapentaenoic acid (EPA) and docosahexaenoic acid (DHA) have demonstrated physiological benefits on blood pressure, heart rate, triglycerides, and likely inflammation, endothelial function, and cardiac diastolic function ${ }^{(51,61-68)}$. Aggregate data from randomized trials, casecontrol and cohort studies, and long-term animal feeding 
experiments indicate $n-6$ PUFAs reduce the risk of CHD relative to lower intakes. Outcomes from epidemiologic studies and controlled clinical trials have shown that replacing SFAs with unsaturated fat (cis MUFA and PUFA) is more successful in reducing the risk of $\mathrm{CHD}$ than simply reducing total fat consumption. Evidence is consistent for a reduced risk of fatal CHD and sudden cardiac death at consumption of around $250 \mathrm{mg}$ /day of EPA plus DHA ${ }^{(61,69)}$.

DHA also plays a major role in development of the brain and retina during foetal development and the first 2 years of life $e^{(13,68,70-78)}$. These findings support the need for recommendations for adequate intakes of preformed DHA in pregnant women, lactating women, and young children. DHA should be considered conditionally essential during early development, since formation of DHA from ALA is limited, highly variable $(1-5 \%)^{(77)}$.

The FAO/WHO 2008 report $^{(8)}$ defines $11 \% \mathrm{E}$ as upperAMRD for total PUFAs in adults, $15 \%$ for infants 6-12 mo., due to a decrease in bioavailability of vitamin E leading to a higher risk of lipid peroxidations, especially when tocopherol supply is not increased accordingly. EFSA report does not provide DRIs for total PUFA, but for specific fatty acids.

\section{n-6 PUFAs: LA}

Table 3 shows recommendations for $n$-6 PUFA, LA, $n$-3 PUFA, EPA and DHA for adults in the different sets compared and Table 4 shows recommendations for infants and children $^{(5,7,8,12-15,17-19,25-38,71,79)}$.

Not all the documents include recommended intakes for LA. There is a wide variation in the recommendations for LA intake for adults between the documents including this value. The lowest limit varies from $2 \% \mathrm{E}$ to $6 \% \mathrm{E}$, while for the upper limit varies from 5 to $10 \% \mathrm{E}$. Some documents provide a single value of adequate intake, established between $2 \% \mathrm{E}$ and $4 \% \mathrm{E}$. The limited information available on LA intake shows a wide variation between population groups.

The FAO/WHO 2008 report $^{(8)}$ and IOM report ${ }^{(5)}$ include AMDR, EAR and AI values for $n-6$ PUFAs. AI for LA is based on median intakes in the USA or lowest mean intakes in Europe.

According to the FAO/WHO 2008 report, the resulting acceptable range for $n$ - 6 fatty acids (LA) is between 2.5 and $9 \% \mathrm{E}$, considering the maximum intake levels of PUFAs (11\%E) and $n-3$ fatty acids $(2 \% \mathrm{E})$. The lower value $(2 \cdot 5 \% \mathrm{E})$ is established taking into account the prevention of deficiency symptoms, whereas the higher value can be part of a healthy heart diet by lowering LDL and TC levels, and therefore the risk for $\mathrm{CHD}^{(8)}$.

The American Heart Association (AHA) ${ }^{(15)}$ recommended intakes of at least $5-10 \% \mathrm{E}$ from $n-6$ PUFA in order to reduce CHD risk, based on evidence from intervention studies with increased LA intake. Controversy raised based on concerns about lipid peroxidation or animal models suggesting that high intakes of LA could promote some cancers and increased likelihood of inflammation and thrombosis. In 2010 a systematic review of the effects of $n-6$ PUFA and LA in particular reported that $n-6$ PUFAs lower total and LDL concentrations, and do not adversely affect blood pressure, platelet aggregation, or inflammation and concluded that an $n$ - 6 PUFA intake above $5 \%$ of energy and ideally about $10 \%$ of energy should be consumed ${ }^{(80)}$.

Ramsden et ll $^{(81)}$, re-evaluated randomized controlled dietary interventions that increased LA intake and pointed out that quite a number of the trials of $n$ - 6 PUFAs actually also increased the intake of the plant $n-3$ PUFA ALA acid or of marine $n-3$ PUFAs and restricted the intake of trans-fatty acids. Results of the analysis of four combined data sets from three trials of enhanced LA intake showed a $13 \%$ increase in relative risk of nonfatal myocardial infarction (MI) and coronary heart disease mortality and a $17 \%$ increase in relative risk of coronary heart disease mortality. The authors concluded that the advice to maintain or increase intake of $n$-6 PUFAs should be reconsidered and analyze the evidence in depth.

Calder and Deckelbaum further discussed this issue and highlighted the need for fatty acid-specific advice based upon the fatty acid-specific evidence base and the need to conduct appropriate studies to fill in the gap ${ }^{(82,83)}$.

\section{n-3 Fatty acids: ALA, DHA, EPA}

EFSA as well as other organizations do not establish recommended intakes for n3-PUFAs but for specific n-3 fatty acids, namely ALA, EPA and DHA ${ }^{(17)}$, or even for docosapentaenoic acid $\mathrm{DPA}^{(35)}$. EFSA sets and adequate intake value (AI) of $0.5 \% \mathrm{E}$ for ALA for all population groups, adults, children, pregnancy and lactation. The AI for the sum EPA + DHA according to this set of recommendations is $250 \mathrm{mg}$ /day for adults; $100 \mathrm{mg}$ /day DHA for children aged $7-24 \mathrm{mo}$. And for pregnancy and lactation, the recommended intake for adults $(\mathrm{EPA}+\mathrm{DHA}=250 \mathrm{mg} / \mathrm{d})$ should be supplemented by $100-200 \mathrm{mg} / \mathrm{d}$ DHA. Governments (France, Belgium, UK, The Netherlands, New Zealand and Australia) and health organizations (FAO/WHO, American Dietetic Association, American Heart Association) now recommend dietary intakes for total $n$-3 PUFA of 1.4 to $2.5 \mathrm{~g} / \mathrm{d}$, with EPA and DHA ranging from 140 to $600 \mathrm{mg} / \mathrm{d}$ depending on the authority issuing guidelines $^{(84)}$.

Recommendations by FAO/WHO 2008 advice and AMDR value for $n-3$ PUFA (ALA + long chain $n-3$ FA) of $0 \cdot 5-2 \% \mathrm{E}$ for adults and $0 \cdot 250-2 \mathrm{~g} / \mathrm{d}$ for $\mathrm{EPA}+\mathrm{DHA}^{(8)}$.

According to the IOM, AMDR for ALA is $0.6-1.2 \% \mathrm{E}$ for adults, ensuring that the lower limit meets the AI for ALA, while the upper limit corresponds to the highest ALA intake from food consumed by individuals in the USA and Canada $^{(72)}$. It is advised that approximately $10 \%$ of the AMDR for ALA can be consumed as EPA and 7\% DHA. The upper AMRD for $n-3$ PUFA is by $3 \mathrm{~g} /$ day, because high supplement intakes of $n$-3 PUFAs have been demonstrated to reduce cytokine production and increase lipid peroxidation ${ }^{(40)}$.

The American Heart Association distinguishes between people without disease $(500 \mathrm{mg} /$ day EPA and DHA), with documented coronary artery diseases ( $1 \mathrm{~g} /$ day), and hypertriglyceridemic patients, who benefit from a high dosage with 3-4g per day of EPA and DHA from fish oil ${ }^{(15)}$. 
Table 3. Recommendations for Polyunsaturated Fatty Acid intakes ${ }^{a}$ in adults according to different bodies

\begin{tabular}{|c|c|c|c|c|c|c|c|}
\hline Region $^{\text {b }}$ & Organization/Country & $n-6(\mathrm{LA})$ & $n-3$ & ALA & EPA & DHA & $\mathrm{EPA}+\mathrm{DHA}$ \\
\hline \multirow{4}{*}{ International } & FAO/WHO, $2008^{(8)}$ & $2.5-9 \% \mathrm{E}$ & $0.5-2 \% E$ & & & & $0.250-2 \mathrm{~g} /$ day \\
\hline & WHO, $2003^{(7)}$ & $5-8 \% \mathrm{E}$ & $1-2 \% E$ & & & & $\begin{array}{l}400-1000 \mathrm{mg} / \text { day }(1-2 \text { servings of } \\
\text { fish } / \text { week })^{c}\end{array}$ \\
\hline & ISSFAL, 1999-2004 ${ }^{(12)}$ & $2 \% \mathrm{E}$ & & $0.70 \% \mathrm{E}$ & & & $>500 \mathrm{mg} / \mathrm{day}$ \\
\hline & $\begin{array}{l}\text { World Association of Perinatal Medicine, } \\
\text { Early Nutrition Academy and Child Health } \\
\text { Foundation (Pregnancy \& lactation) }\end{array}$ & & & & & $200-300 \mathrm{mg} / \mathrm{day}$ & \\
\hline \multirow[t]{8}{*}{ North America } & AHA 2006; $2009^{(14,15)}$ & & & & $\begin{array}{l}\text { More emphasis } \\
\text { on healthy } \\
\text { food patterns }\end{array}$ & & $\begin{array}{l}1 \mathrm{~g} / \mathrm{d} \text { (secondary prevention); } 2 \text { portions } \\
\text { fatty fish/week. Primary prevention: } \\
500 \mathrm{mg} / \text { day }^{\mathrm{d}}\end{array}$ \\
\hline & IOM 2002/2005(5) & $\begin{array}{l}\text { 5-10\% LA } \\
\text { (M: } 17 \mathrm{~g} / \text { day; } \\
\text { F:12 g/day) }\end{array}$ & $0.6-1.2 \% E$ & $\begin{array}{l}\text { Al: M: } 1 \cdot 6 \mathrm{~g} ; \mathrm{F}: 1 \cdot 1 \mathrm{~g} \\
\text { (AMDR } 0 \cdot 6-1 \cdot 2 \% \mathrm{E})\end{array}$ & & & Al: $0.6 \% \mathrm{E} . \leq 10 \% \mathrm{E} \mathrm{Al}(140 \mathrm{mg})$ \\
\hline & ADA USA \& Canada, 2007(25) & $\begin{array}{l}\text { 3-10\% } \mathrm{E} \\
\text { (M: } 17 \mathrm{~g} / \text { day; } \\
\text { F: } 12 \mathrm{~g} / \text { day) }\end{array}$ & & $\begin{array}{l}\text { Al: M: } 1.6 \mathrm{~g} / \text { day; } \\
\text { F: } 1.1 \mathrm{~g} / \text { day }\end{array}$ & & & $(500 \mathrm{mg} / \mathrm{d} \mathrm{EPA}+\mathrm{DHA})$ \\
\hline & USDA Dietary Guidelines for Americans, $2010^{(18)}$ & $5-10 \% \mathrm{E}$ & & & & & $\begin{array}{l}\text { Increase the amount and variety of sea- } \\
\text { food consumed by choosing seafood } \\
\text { in place of some meat and poultry }\end{array}$ \\
\hline & American Diabetes Association, $2008^{(26)}$ & & & & & & Two or more servings of fish per week \\
\hline & EURODIET, $2000^{(27)}$ & $4-8 \mathrm{~g}$ & Marine & $2 \mathrm{~g}$ & & & $200 \mathrm{mg}$ \\
\hline & EFSA, $2010^{(19)}$ & $4 \% \mathrm{E}$ & & $0.50 \% \mathrm{E}$ & & & $250 \mathrm{mg}$ \\
\hline & $\begin{array}{l}\text { Fourth Joint Task Force of the European Society } \\
\text { of Cardiology, } 2007^{(20)}\end{array}$ & & & & & & $\begin{array}{l}1 \mathrm{~g} / \mathrm{d} \text { (secondary prevention); } 2 \text { portions } \\
\text { fatty fish/week }\end{array}$ \\
\hline \multirow[t]{6}{*}{ Europe } & UK Committee on Nutrition (COMA, 1991) ${ }^{(3)}$ & $1 \% \mathrm{E}$ & & $0.2 \% \mathrm{E}$ & & & $450 \mathrm{mg}$ as two servings of fish $/$ week $^{\mathrm{e}}$ \\
\hline & Dutch Health Council, $2001-2006^{(29,30)}$ & $2 \% \mathrm{E}$ & $1 \% \mathrm{E}$ & & & & $450 \mathrm{mg}$ as two servings of fish $/$ week $^{\mathrm{e}}$ \\
\hline & Consensus statement ${ }^{(71)}$ & & & & & $\begin{array}{l}\geq 200 \mathrm{mg} \text { pregnancy } \\
\text { and lactation }\end{array}$ & \\
\hline & $\begin{array}{l}\text { AFFSA, CNERNA \& CNRS. France, } \\
2001-2005^{(31)}\end{array}$ & $4 \% \mathrm{E}$ & & $0.8 \% \mathrm{E}$ & & $0.05 \% E(120 \mathrm{mg} / \mathrm{d})$ & $500 \mathrm{mg} / \mathrm{d}$ \\
\hline & Conseil Supérieur de la Santé. Belgium, $2009^{(32)}$ & $\begin{array}{l}2 \% \mathrm{E} \\
5-9 \% \mathrm{FE}\end{array}$ & $1 \cdot 3-2 \cdot 0 \% \mathrm{E}$ & $>1 \% E$ & & & $>0.3 \% \mathrm{E}(\mathrm{aprox} 667 \mathrm{mg} / \mathrm{d})$ \\
\hline & SENC. Spain, $2011^{(34)}$ & $5 \% \mathrm{E}$ & $1-2 \% \mathrm{E}$ & $1-2 \% \mathrm{E}$ & & $200 \mathrm{mg}$ & $500-1000 \mathrm{mg} / \mathrm{d}$ \\
\hline \multirow[t]{5}{*}{ Asia-Pacific } & NHRC. Australia \& New Zealand, 2006 $6^{(35)}$ & $\begin{array}{r}\mathrm{M}: 13 \mathrm{~g} / \mathrm{d} \\
\mathrm{F}: 8 \mathrm{~g} / \mathrm{d}\end{array}$ & Increase & M: $1.3 \mathrm{~g} / \mathrm{d} ; \mathrm{F}: 0.8 \mathrm{~g} / \mathrm{d}$ & & & $\begin{array}{l}\mathrm{M}: 160 \mathrm{mg} / \mathrm{d} ; \mathrm{F}: 90 \mathrm{mg} / \mathrm{d}(\mathrm{EPA}+\mathrm{DHA} \\
\quad+\mathrm{DPA})(<3000 \mathrm{mg} / \mathrm{d})\end{array}$ \\
\hline & $\begin{array}{l}\text { NHRC. Australia \& New Zealand, } 2006^{(35)} \\
\text { Pregnancy }\end{array}$ & $10 \mathrm{~g} / \mathrm{d}$ & & $1 \mathrm{~g} / \mathrm{d}$ & & & $\begin{array}{l}\text { 14-18 yr: } 110 \mathrm{mg} / \mathrm{d} ; 19-50 \mathrm{yr}: 115 \mathrm{mg} / \mathrm{d} \\
(<3000 \mathrm{mg} / \mathrm{d})\end{array}$ \\
\hline & $\begin{array}{l}\text { NHRC. Australia \& New Zealand, 2006 } \\
\text { Lactation }\end{array}$ & $12 \mathrm{~g} / \mathrm{d}$ & & $1.2 \mathrm{~g} / \mathrm{d}$ & & & $\begin{array}{l}14-18 \mathrm{yr}: 140 \mathrm{mg} / \mathrm{d} ; 19-50 \mathrm{yr}: 145 \mathrm{mg} / \mathrm{d} \\
(<3000 \mathrm{mg} / \mathrm{d})\end{array}$ \\
\hline & National Institute of Nutrition. India, $2009^{(37)}$ & & Increase & & & & \\
\hline & $\begin{array}{l}\text { Department of Nutrition, Ministry of Health } \\
\text { Oman. Oman, } 2009^{(38)}\end{array}$ & $5-8 \% \mathrm{E}$ & $1-2 \% E$ & & & & \\
\hline
\end{tabular}

LA: linoleic acid; EPA: eicosapentaenoic acid; DHA: docosahexaenoic acid; ALA: alpha-linolenic acid. \%E: \% Energy intake.

Al: Adequate Intake; AMDR: Acceptable Macronutrient Distribution Ranges.

M: males; F: Females.

${ }^{a}$ Recommendations for $\mathrm{n}-6, \mathrm{n}-3$ and ALA are expressed either as percent energy intake or g/day.

${ }^{\circ}$ Region: Continent or region where recommendations apply.

${ }^{\circ}$ WHO supports recommended intake levels of EPA + DHA of $400-1000 \mathrm{mg} /$ day. This intake levels can be achieved by regular consumption of fish (1-2 servings of fish/week).

${ }^{\mathrm{d}} \mathrm{AHA}$ recommendation of EPA + DHA intake for primary prevention is $500 \mathrm{mg} /$ day. This intake levels can be achieved by regular consumption of fish (2 portions of fish/week). For secondary prevention recommended intake

level is $1 \mathrm{~g} / \mathrm{d}$.

${ }^{e}$ According to these documents, recommended intake levels of EPA + DHA ( $450 \mathrm{mg} /$ day) should be achieved by regular fish consumption, as two servings of fish weekly 
Table 4. Recommendations for polyunsaturated fatty acid intakes ${ }^{a}$ in infants and children according to different bodies

\begin{tabular}{|c|c|c|c|c|c|c|c|c|}
\hline Organization/Country & Age group & n6 (LA) & n3 & EPA & $\mathrm{DHA}$ & $\mathrm{EPA}+\mathrm{DHA}$ & ALA & AA \\
\hline \multirow[t]{3}{*}{$\mathrm{FAO} / \mathrm{WHO}, 2008^{(8)}$} & $0-6$ months & $\begin{array}{l}\text { Essential and } \\
\text { indispensable }\end{array}$ & & & $\begin{array}{c}0.1-0.18 \% \mathrm{E} \text { (No upper } \\
\text { value within the HM } \\
\text { range up to } 0.75 \% \mathrm{E} \text { ) }\end{array}$ & & $\begin{array}{l}\text { Essential and } \\
\text { indispensable } \\
0.2-0.3 \% \mathrm{E}\end{array}$ & $0.2-0.3 \% E$ \\
\hline & $6-24$ months & $\begin{array}{c}\text { 3.0-4.5\%E } \\
\text { (U-AMDR: } \\
\quad<10 \% E)\end{array}$ & & & $10-12 \mathrm{mg} / \mathrm{kg}$ & & $\begin{array}{l}0.4-0.6 \% \mathrm{E} \text { (U-AMDR: } \\
<3 \% \mathrm{E})\end{array}$ & \\
\hline & $\begin{array}{l}2-4 \text { years. } \\
4-6 \text { years } \\
6-10 \text { years }\end{array}$ & & & & & $\begin{array}{l}100-150 \mathrm{mg} \\
150-200 \mathrm{mg} \\
200-250 \mathrm{mg}\end{array}$ & & \\
\hline ISSFAL, 1999-2004 ${ }^{(12)}$ & & & & & $0.35 \%$ total fat & & & $0.5 \%$ total fat \\
\hline $\begin{array}{l}\text { World Association of } \\
\text { Perinatal Medicine, } \\
\text { Early Nutrition } \\
\text { Academy and Child Health } \\
\text { Foundation (Pregnancy } \\
\text { \& lactation) })^{(13)}\end{array}$ & & & & $\begin{array}{l}\text { Infant formulas } \\
\text { and baby foods: } \\
\leq \mathrm{DHA}\end{array}$ & $\begin{array}{l}\text { Infant formulas and } \\
\text { baby foods: } \\
0.2-0.5 \% \\
\text { of fatty acids }\end{array}$ & & & \\
\hline \multirow[t]{3}{*}{ EFSA, 2010 (19) } & $6-12$ months & $4 \% E$ & & & & $100 \mathrm{mg}$ & $0.50 \% \mathrm{E}$ & \\
\hline & $1-3$ years & $4 \% \mathrm{E}$ & & & & $100 \mathrm{mg}$ & $0.50 \% \mathrm{E}$ & \\
\hline & $>4$ years & $4 \% \mathrm{E}$ & & & & & $0.50 \% \mathrm{E}$ & \\
\hline $\begin{array}{l}\text { Dutch Health Council, } \\
2001-2006^{(29,30)}\end{array}$ & & & & & $\begin{array}{l}20 \mathrm{mg} / \mathrm{kg} \text { body } \\
\text { weight }\end{array}$ & & & \\
\hline \multirow{4}{*}{$\begin{array}{l}\text { Conseil Supérieur de la } \\
\text { Santé.Belgium, 2009 }\end{array}$} & $0-6$ months & $4.4 \mathrm{~g} / \mathrm{d}$ & & & & & $0.5 \mathrm{~g} / \mathrm{d}$ & \\
\hline & $6-12$ months & $4.6 \mathrm{~g} / \mathrm{d}$ & & & & & $0.5 \mathrm{~g} / \mathrm{d}$ & \\
\hline & $1-3$ years & $2-5 \% \mathrm{E}$ & & $0.05-0.15 \% \mathrm{E}$ & $0.10-0.40 \% E$ & & $0.45-1.50 \% \mathrm{E}$ & $0.10-0.25 \% \mathrm{E}$ \\
\hline & $3-18$ years & $2-5 \% \mathrm{E}$ & & $0.05-0.15 \% \mathrm{E}$ & $0.10-0.40 \% \mathrm{E}$ & & $0.45-1.50 \% \mathrm{E}$ & $0.10-0.25 \% \mathrm{E}$ \\
\hline \multirow{6}{*}{$\begin{array}{l}\text { NHRC. Australia \& } \\
\text { New Zealand, } 2006^{(35)}\end{array}$} & $0-6$ months & $4.4 \mathrm{~g} / \mathrm{d}$ & $0.5 \mathrm{~g} / \mathrm{d}$ & & & & & \\
\hline & $7-12$ months & $4.6 \mathrm{~g} / \mathrm{d}$ & $0.5 \mathrm{~g} / \mathrm{d}$ & & & & & \\
\hline & $1-3$ years & $5 \mathrm{~g} / \mathrm{d}$ & & & & $40 \mathrm{mg} / \mathrm{d}(<3000 \mathrm{mg} / \mathrm{d})$ & $0.5 \mathrm{~g} / \mathrm{d}$ & \\
\hline & $4-8$ years & $8 \mathrm{~g} / \mathrm{d}$ & & & & $55 \mathrm{mg} / \mathrm{d}(<3000 \mathrm{mg} / \mathrm{d})$ & $0.8 \mathrm{~g} / \mathrm{d}$ & \\
\hline & $9-13$ years & M:10 g/d; F: $8 \mathrm{~g} / \mathrm{d}$ & & & & $70 \mathrm{mg} / \mathrm{d}(<3000 \mathrm{mg} / \mathrm{d})$ & M:1.0 g/d; F: $0.8 \mathrm{~g} / \mathrm{d}$ & \\
\hline & $14-18$ years & $\mathrm{M}: 12 \mathrm{~g} / \mathrm{d} ; \mathrm{F}: 8 \mathrm{~g} / \mathrm{d}$ & & & & $\begin{array}{c}\mathrm{M}: 125 \mathrm{mg} / \mathrm{D} ; \mathrm{F}: 85 \mathrm{mg} / \mathrm{d} \\
(<3000 \mathrm{mg} / \mathrm{d})\end{array}$ & $\mathrm{M}: 1.2 \mathrm{~g} / \mathrm{d} ; \mathrm{F}: 0.8 \mathrm{~g} / \mathrm{d}$ & \\
\hline
\end{tabular}

U-AMDR: Upper limit of Acceptable Macronutrient Distribution Ranges.

LA: linoleic acid; EPA: eicosapentaenoic acid; DHA: docosahexaenoic acid; ALA: alpha-linolenic acid. \%E: \% Energy intake; HM: human milk.

M: males; F: Females.

${ }^{a}$ Recommendations for $n-6, n-3$ and ALA are expressed either as percent energy intake or g/day. 
The Dietary Guidelines for Americans advise to increase consumption of $n-3$ fatty acids by consuming two servings of seafood per week which provide an average of $250 \mathrm{mg} /$ day of omega-3 fatty acids from marine sources. These reports note there is limited evidence suggesting an association between consumption of fatty acids in fish and reduced risk of mortality from cardiovascular disease for the general population, and other sources of EPA and DHA may provide similar benefits, although more research is needed ${ }^{(18)}$.

Recommendations from different organizations, for primary prevention of coronary disease, advice consumption of at least two servings of fish per week. Recommendations for long chain $n$-3 FA (EPA + DHA) vary between 250 and $667 \mathrm{mg} / \mathrm{d}$.

In older infants, DHA intakes at levels of 50 to $100 \mathrm{mg}$ per day have been found effective for visual function in the complementary feeding period and are considered to be adequate for that period. An AI of $100 \mathrm{mg}$ DHA for older infants (>6 mo.) and young children below the age of 24 months. The currently available evidence does not permit the definition of an age specific quantitative estimate of an adequate dietary intake for EPA and DHA for children aged 2 to 18 years. However, dietary advice for children should be consistent with advice for the adult population ${ }^{(71,72,73)}$.

Evidence supporting recommendations for adults is mostly related to primary and secondary prevention of CVD. ALA consumption is suggested to probably reduce CHD risk. Although clinical benefits are not consistent in all studies, new experimental and prospective observational studies support that ALA consumption reduces the incidence of CHD. Physiological benefits of EPA and DHA consumption have been demonstrated on blood pressure, heart rate, triglycerides, and likely inflammation, endothelial function, and cardiac diastolic function, and consistent evidence for a reduced risk of fatal CHD and sudden cardiac death at consumption of around $250 \mathrm{mg}$ /day of EPA plus DHA. A minimum intake of $250 \mathrm{mg}$ /day of EPA and DHA, obtained from seafood consumption, has been suggested for primary prevention of CHD death ${ }^{(61)}$.

In 2002, the IOM concluded that insufficient data were available to set an RDA or an AI for EPA and/or DHA. An estimated average requirement was not established because of the lack of data in support of an (n-3) PUFA requirement for healthy individuals and for adequate growth and neural development ${ }^{(70,85)}$.

The data from the secondary and primary prevention studies support the theory that the intake of $n-3$ PUFAs reduces all-cause mortality, cardiac and sudden death, and stroke ${ }^{(86)} \cdot n-3$ PUFAs appear to confer cardiovascular health benefits mainly through EPA and DHA enrichment of membrane phospholipids. The observational evidence that a strong inverse relationship is present between $n-3$ PUFAs or fish intake and risk of CHD is convincing; three well-designed randomized controlled trials (GISSI $^{(69)}$, DART I ${ }^{(87)}$ and JELIS ${ }^{(88)}$ reported significant benefits for $n$-3 PUFAs in patients with established CHD. The conclusions of some recent meta-analysis support these findings ${ }^{(59,89)}$.

However, other studies such as DART-2 ${ }^{(90)}$; OMEGA trial ${ }^{(91)}$, the Alpha Omega trial ${ }^{(92)}$ and meta-analysis including them have not reported a beneficial effect ${ }^{(65,93)}$. Some of these studies have been criticized for ignoring baseline $n-3$ PUFA dietary intake, n-6 PUFA or antioxidant intake, among other reasons. Unfolding evidence contributes to the debate with new trials supporting that $n-3$ PUFAs may exert beneficial effects in the prevention of atrial fibrillation ${ }^{(94)}$, but others yielded conflicting results ${ }^{(95)}$. The benefits of $n-3$ PUFAs on neurological functions are recognized, although more research is needed in this area ${ }^{(96)}$.

In most populations, current intakes of PUFA and especially $n-3$ PUFA are insufficient for optimal health ${ }^{(40)}$. Overall, the evidence about seafood-derived $n-3$ PUFA is convincing that modest consumption of fish or fish oil reduces CHD death, and may favourably affect other clinical outcomes. Regarding plant-derived $n$-3 PUFA, there is currently only possible evidence that ALA consumption prevents CVD.

The evidence supporting recommendations for pregnant and lactating women is based on optimal pregnancy outcomes and on possible beneficial effects on foetal and infant development. Currently there is a lack of sufficient evidence to link levels of dietary intake of DHA and/or EPA to improved physical, mental or other functional benefits in children. Quantitative dietary intake recommendations for children cannot be established at this time ${ }^{(70)}$.

One of the main considerations when trying to meet current recommendations for $n-3$ fatty acids is that current intake of PUFAs consists primarily of $n-6$ fatty acids. The competition for desaturases and elongases in $n-3$ and $n-6$ PUFA metabolism results in inverse effects on tissue concentrations of these fatty acids. This is of even greater concern in vegetarians and vegans, who have relatively high intakes of LA combined with low intakes of EPA and $\mathrm{DHA}^{(97)}$. Another consideration for meeting recommendations for marine-derived $n-3$ fatty acids is that some populations do not consume fish because of concerns about environmental toxins, taste preferences, or ethical reasons. Studies have shown that certain fish contain high levels of environmental toxins, such as mercury and polychlorinated biphenyls (PCBs), a challenge faced when increasing dietary fish intake. Of particular importance is the neurologic damage to developing foetuses and young children caused by toxic levels of methylmercury ${ }^{(51)}$.

In this sense the European Food Safety Authority and the joint FAO/WHO expert consultation concluded that women of childbearing age consuming two fish servings per week should generally not exceed the provisional tolerable weekly intake of environmental pollutants ${ }^{(98)}$. The US Food and Drug Administration advise following recommendations about consumption of certain fish high in mercury because of potential harmful effects to the foetus or infant ${ }^{(99)}$.

\section{n-6 PUFA:n-3 PUFA ratio}

A lower ratio of $n-6$ to $n$ - 3 fatty acid consumption has been recommended under the assumption that higher intakes of $n$ - 6 fatty acids may reduce the formation of anti-inflammatory mediators from $n$ - 3 fatty acids ${ }^{(67)}$. However, this hypothesis is not supported by studies in humans ${ }^{(68)}$. At moderate intakes of 5\%-8\% E, increasing LA intake does not result in increased arachidonic acid in plasma or platelet lipids, and does not increase formation of proinflammatory mediators ${ }^{(100)}$ 
The advisory published by the American Heart Association (AHA) on $n-6$ fatty acids and cardiovascular risk ${ }^{(15)}$ in 2009 stating that 'consumption of at least $5 \%$ to $10 \%$ of energy from $n$ - 6 PUFAs reduces risk of CHD relative to lower intakes' raised the controversy.

A focus on dietary ratios suggests that lowering $n$ - 6 fatty acid intake would have the same health effects as increasing $n-3$ fatty acid intake. Based on both evidence and conceptual limitations, there is no scientific rationale for the continued recommendation of a specific ratio of $n-6$ to $n$ - 3 fatty acids or LA to ALA. The focus on ratios, rather than on levels of intake of each type of PUFA, has many conceptual and biological limitations ${ }^{(82)}$.

The use of the $n-6$ to $n$ - 3 fatty acid ratio ignores the contribution of each class of fatty acid and even individual fatty acids. This approach assumes that all $n-6$ fatty acids and all $n-3$ fatty acids are biologically equivalent to one another which is not correct ${ }^{(62,81,101)}$, and supports that the actions of $n-6$ and $n-3$ fatty acids always oppose one another ${ }^{(82)}$. The bulk of current evidence suggests that it is the absolute intakes of specific $n-6$ and $n-3$ PUFA that are associated with many different endpoints ${ }^{(102-104)}$. Thus, considerations about adequate intakes for both $n-3$ and $n-6$ fatty acids are relevant. The use of a ratio can disguise extremely low or very high intakes of $n-6$ and/or $n-3$ fatty acids ${ }^{(83)}$.

\section{Trans}

Overall, recommendations for trans fatty acids intake advice to limit intake below $1 \% \mathrm{E}$ or to keep trans FA intake as low as possible.

Evidence supporting these recommendations is based on the effects of trans fatty acids on plasma lipids and cardiovascular disease. Trans fatty acid consumption has adverse effects on serum lipids, including increasing LDLC, lowering HDL-C, increasing TGs and lipoprotein(a), increasing ApoB levels, and decreasing ApoA1 levels. Moreover, they adversely influence LA and ALA metabolism and prostaglandin balance by inhibiting the enzyme delta 6-desaturase ${ }^{(105-108)}$.

In the USA average adult's daily ruminant trans fatty acid intake of both men and women is about $1.2 \mathrm{~g}$, which correspond to $0.5 \% \mathrm{E}$. If similar average intake values from industrially hydrogenated fat could be anticipated, then the trans fatty acid intake from all sources should be limited to $1 \% \mathrm{E}$.

The Food and Drug Administration and EFSA have required that trans-fat be listed on the nutrition labelling. However, manufacturers are allowed to list foods with trans-fat content less than $0.5 \mathrm{~g}$ as $0 \mathrm{~g}$ of trans-fat. People may see a few products that list $0 \mathrm{~g}$ trans-fat on the label, while the ingredient list will have 'shortening,' 'partially hydrogenated vegetable oil,' or 'hydrogenated vegetable oil' on it. Nutrition education on label reading and portion control is essential in keeping trans-fat intake as low as possible ${ }^{(109)}$.

\section{Cholesterol}

Most documents do not include a recommended intake for cholesterol. When advised, the recommended daily intake level is below $300 \mathrm{mg} /$ day. The FAO/WHO 2008 report do not include this recommendation. The EFSA report and many countries, such as Canada, Korea, New Zealand and India do not set an upper limit for dietary cholesterol, focusing instead on controlling the intake of saturated fat and trans fat, which are the major determinants of blood cholesterol concentrations. Epidemiologic studies and clinical trial results suggest that compelling evidence is lacking for limiting cholesterol intake to $300 \mathrm{mg} / \mathrm{d}^{(110)}$.

\section{Dietary guidelines}

Most reports advice to control total calorie intake to manage body weight; to choose lean meat cuts, low fat dairy products and increase consumption of fruit and vegetables, whole-grain cereals and fish.

Recommendations tend to focus on general dietary patterns and increased physical activity rather than on nutrients. During past decades, advice to decrease fat intake may have induced unwanted dietary changes that may have contributed to the increase in overweight and obesity. It is the sum of all dietary and lifestyle changes that produces the intervention's net health effects. To avoid this possibility in the future, specific and transparent classification of the quality of the evidence should form the basis for guidelines development. Dietary guidelines need explicit standards of evidence. The strengths and limitations of evidence should be provided in easy-to-understand language.

An adaptation of evidence ratings has been suggested which consider both the quality of the evidence and the net benefit of an intervention. The net benefit recognizes the potential for harm. The process includes a broader category for which no recommendation should be made, intended to provide the appropriate level of caution in the process of issuing guidelines ${ }^{(42)}$.

\section{Conclusions}

Recommendations regarding fat intake share similar figures regarding total fat intake, SFA and TFA. Asian recommendations considering prevailing food and health patterns in the region, advice lower total fat intake. Many sets do not include a recommendation on cholesterol intake. Most recent documents provide advice regarding n-3 PUFA, ALA, EPA and DHA. Despite efforts to develop evidence based nutrient recommendations and dietary guidelines that may contribute to enhance health, there are still many gaps in research that need to be adequately addressed. In particular, further assessment of specific effects of DHA and EPA during pregnancy, lactation and infancy should be conducted on neuropsychological function, immune response, and rates of infection in the infant. There is limited information on doseresponse effects of EPA and DHA on CHD, inflammation and immune response and even a large intervention trial on $n-3$ PUFA and primary prevention of $\mathrm{CHD}$ and metabolic syndrome.

The World Cancer Research Found (WCRF) and the American Institute for Cancer Research (AICR) published in 
1997 a comprehensive analysis of the literature on diet, physical activity and cancer and second expert report on $2007^{(43)}$. Since then a continuous update project has been established $^{(111)}$.

In line with this, as part of implementing the outcomes and recommendations of the WHO Nutrition Programme Review undertaken in 2008, the Department of Nutrition for Health and Development (NHD) established the WHO Nutrition Guidance Expert Advisory Group (NUGAG) guided by the WHO Steering Committee for Nutrition Guidelines Development. NUGAG started in 2010 and includes four working groups: 1) micronutrients, 2) diet and health, and 3) nutrition in life course and undernutrition and 4) monitoring and evaluation. The topics to be addressed by second subgroup, diet and health, include the effects of the level of total fat intake on obesity and other related noncommunicable diseases (NCDs) and the effects of sugars intake on health ${ }^{(112)}$. The group held a third meeting in Geneva in March 2011.

In the near future, it would be desirable that all documents including nutrient recommendations and dietary guidelines follow standardized protocols that can contribute to provide solid evidence background to the recommendations. Additionally, it would be desirable that responsible bodies and organizations could plan timelines for regularly updating recommendations on light of the emerging evidence.

\section{Acknowledgements and disclosures}

The preparatory meetings for this series of reviews on fat and health were funded by Puleva Food. Neither Javier Aranceta nor Carmen Pérez-Rodrigo have conflicts of interest to disclosure.

Javier Aranceta and Carmen Pérez-Rodrigo contributed to the design of the strategy for the literature search, double screened and selected the retrieved documents. Javier Aranceta prepared the main outline of the manuscript. Javier Aranceta and Carmen Pérez-Rodrigo contributed to the preparation of the manuscript.

\section{References}

1. Gifford D (2002) Dietary Fats, Eating Guides and Public Policy: History, Critique, and Recommendations. Am J Med 113, 89S-106S, 9B.

2. Kritchevsky D (1998) History of Recommendations to the Public about Dietary Fat. J Nutr 128, 449S-452S.

3. Committee on Medical Aspects of Food Policy (COMA) (1991) Dietary Reference Values (DRVs) for Food Energy and Nutrients for the UK. Report on Health and Social Subjects 41. London: The Stationary Office.

4. Yates AA (1998) Overview of Key Nutrients: Energy and Macronutrient Aspects. Nutr Rev 56, S29-S33.

5. Institutes of Medicine (IOM) (2002/2005) Panel on Macronutrients, Panel on the Definition of Dietary Fiber, Subcommittee on Upper Reference Levels of Nutrients, Subcommittee on Interpretation and Uses of Dietary Reference Intakes, and the Standing Committee on the Scientific Evaluation of Dietary Reference Intakes. DRI Dietary reference intakes for Energy, Carbohydrate, Fiber, Fat,
Fatty Acids, Cholesterol, Protein, and Amino Acids. Washington, DC: The National Academies Press.

6. FAO (1994) Fats and oils in human nutrition. FAO. Food and nutrition paper $\mathrm{N}^{\circ} 57$ Rome: FAO.

7. WHO-FAO (2003) Diet, nutrition and the prevention of chronic diseases. Report of a Joint WHO/FAO Expert Consultation. WHO Technical Report Series 916 Geneva: WHO.

8. FAO-WHO (2010) Fats and Fatty Acids in Human Nutrition. Rome: FAO Food and nutrition paper \# 91. Report of an expert consultation. Geneva, November 10-14, 2008.

9. Smit LA, Mozaffarian D \& Willett W (2009) Review of Fat and Fatty Acid Requirements and Criteria for Developing Dietary Guidelines. Ann Nutr Metab 55, 44-55.

10. Moher D, Liberati A, Tetzlaff J \& Altman DG, The PRISMA Group (2009) Group Preferred Reporting Items for Systematic Reviews and Meta-Analyses: The PRISMA Statement. PLoS Med 6, e1000097. doi:10·1371/journal. pmed1000097.

11. Systematic Reviews Collaborative Tool (SysCollab) [Computer program] (2010). Granada, Spain: University of Granada.

12. ISSFAL, International Society for the Study of Fatty Acids and Lipids (2004) Report of the Sub-Committee on Recommendations for intake of polyunsaturated fatty acids in healthy adults. ISSFAL: Brighton, UK.

13. Koletzko B, Lien E, Agostoni C, et al. (2008) The roles of longchain polyunsaturated fatty acids in pregnancy, lactation and infancy: review of current knowledge and consensus recommendations. J Perinat Med 36, 5-14.

14. American Heart Association Nutrition Committee, Lichtenstein AH, Appel LJ, Brands M, et al. (2006) Diet and lifestyle recommendations revision 2006: a scientific statement from the American Heart Association Nutrition Committee. Circulation 114, 82-96.

15. Harris WS, Mozaffarian D, Rimm E, et al. (2009) Omega-6 Fatty Acids and Risk for Cardiovascular Disease: A Science Advisory From the American Heart Association Nutrition Subcommittee of the Council on Nutrition, Physical Activity, and Metabolism; Council on Cardiovascular Nursing; and Council on Epidemiology and Prevention. Circulation 119, 902-907.

16. Anderson GH \& Zlotkin SH (2000) Developing and implementing food-based dietary guidance for fat in the diets of children. Am J Clin Nutr 72, Suppl, 1004S-1009S.

17. Gidding SS, Dennison BA, Birch LL, et al. (2006) Dietary Recommendations for Children and Adolescents: A Guide for Practitioners. Pediatrics 117, 544.

18. U.S. Department of Agriculture, U.S. Department of Health and Human Services (2010) Dietary Guidelines for Americans, 2010, 7th Edition Washington, DC: U.S. Government Printing Office, December.

19. EFSA Panel on Dietetic Products, Nutrition, and Allergies (NDA) (2010) Scientific Opinion on Dietary Reference Values for fats, including saturated fatty acids, polyunsaturated fatty acids, monounsaturated fatty acids, trans fatty acids, and cholesterol. The EFSA Journal 8, 1461.

20. Fourth Joint Task Force of the European Society of Cardiology (2007) European guidelines on cardiovascular disease prevention in clinical practice. Eur J Cardiovasc Prev Rehab 14, suppl 2, S1-S113.

21. Doets EL, de Wit LS, Dhonukshe-Rutten RAM, et al. (2008) Current micronutrient recommendations in Europe: towards understanding their differences and similarities. Eur J Nutr 47, Suppl. 1, 17-40.

22. Pavlovic M, Prentice A, Thörsdottir I, et al. (2007) Challenges in Harmonizing Energy and Nutrient Recommendations in Europe. Ann Nutr Metab 51, 108-114. 
23. Taylor CL (2008) Framework for DRI Development. Washington, Institute of Medicine. Available at URL: (http:// www.iom.edu/Object.File/Master/54/358/DRI\%20Framework. pdf) (accessed May 20th 2011).

24. Iglesia I, Doets EL, Bel-Serrat S, et al. (2010) Physiological and public health basis for assessing micronutrient requirements in children and adolescents. The EURRECA network. Maternal \& Child Nutr 6, 84-99.

25. Kris-Etherton PM \& Innis S (2007) Position of the American Dietetic Association and Dietitians of Canada: dietary fatty acids. J Am Diet Assoc 107, 1599-1611.

26. American Diabetes Association (2008) Nutrition Recommendations and Interventions for Diabetes. A position statement of the American Diabetes Association. Diabetes Care 31, Suppl, S61-S78.

27. Ferroluzzi A \& James WPT (2001) European diet and public health: The continuing challenge. Public Health Nutr 4, 2A $275-292$.

28. DACH (2002) German Nutrition Society (Dge). Austrian Nutrition Society (Öge); Referenzwerte Für Die Nährstoffzufubr/Reference Values For Nutrient Intake. Umschau/Braus: Frankfurt/Main.

29. Gezondheidsraad; Health Council of the Netherlands (2002) Dietary reference intakes. Energy, proteins, fats, and digestible carbohydrates. The Hague, NL: The Health Council of the Netherlands.

30. Health Council of the Netherlands (2006) Guidelines to a bealthy diet 2006. The Hague: Health Council of the Netherlands: publication no: 2006/21E.

31. Martin A (Editor) (2001) Apports nutritionnels conseilles pour la population Française, 3rd ed. France: Tech. \& Doc Lavoisier.

32. Conseil Supérieur de la Santé (2009) Recommandations nutritionnelles pour la Belgique, Révision 2009. Publication Du Conseil Superieur De La Sante $N^{\circ}$ 8309. Bruxelles, 28 October 2009.

33. Becker W, Lyhne N, Pedersen AN, et al. (2004) Nordic Nutrition Recommendations 2004/integrating nutrition and physical activity. Scan J Nutr 48, 178-187.

34. Aranceta J, Serra Majem Ll, Grupo Colaborativo para la actualización de los Objetivos Nutricionales para la Población Española (2011). Objetivos Nutricionales para la Población Española 2011. Consenso de la Sociedad Española de Nutrición Comunitaria (SENC). Rev Esp Nutr Comunitaria 17, 178-199.

35. National Health and Medical Research Council, Department of Health and Ageing (2006) Nutrient Reference Values for Australia and New Zealand Including Recommended Dietary Intakes. Canberra: Commonwealth of Australia.

36. Jang YA, Lee HS, Kim BH, et al. (2008) Revised dietary guidelines for Koreans. Asia Pac J Clin Nutr 17, S1, 55-58.

37. A Report of the Expert Group of the Indian Council Of Medical Research (2009) Nutrient Requirements and Recommended Dietary Allowances for Indians. Hyderabad. National Institute of Nutrition, Indian Council of Medical Research

38. Alasfoor D, Rajab H, Al-Rassas B, et al. (2009) Oman Food Based Dietary Guidelines Technical background and description. Department of Nutrition, Ministry of Health Oman.

39. Bray GA \& Popkin BM (1998) Dietary fat intake does affect obesity! Am J Clin Nutr 68, 1157-1173.

40. Elmadfa I \& Kornsteiner M (2009) Fats and Fatty Acid Requirements for Adults. Ann Nutr Metab 55, 56-75.
41. Uauy R (2009) Dietary Fat Quality for Optimal Health and Well-Being: Overview of Recommendations. Ann Nutr Metab 54, Suppl. 1, 2-7.

42. Marantz PR, Bird ED \& Alderman MH (2008) A Call for Higher Standards of Evidence for Dietary Guidelines. $\mathrm{Am}$ J Prev Med 34, 234-240.

43. World Cancer Research Fund/American Institute for Cancer Research (2007) Food, Nutrition, Physical Activity, and the Prevention of Cancer: a Global Perspective. Washington: WCRF/AICR

44. Nordmann AJ, Nordmann A, Briel M, et al. (2006) Effects of low-carbohydrate vs. low-fat diets on weight loss and cardiovascular risk factors: a meta-analysis of randomized controlled trials. Arch Intern Med 166, 285-293.

45. Howard BV, Van Horn L, Hsia J, et al. (2006) Low-Fat Dietary Pattern and Risk of Cardiovascular Disease. The Women's Health Initiative Randomized Controlled Dietary Modification Trial. JAMA 295, 655-666.

46. Melanson EL, Astrup A \& Donahoo WT (2009) The relationship between dietary fat and fatty acid intake and body weight, diabetes, and the metabolic syndrome. Ann Nutr Metab 55, 229-243.

47. Krauss RM, Eckel RH, Howard B, et al. (2000) AHA Dietary Guidelines : Revision 2000: A Statement for Healthcare Professionals From the Nutrition Committee of the American Heart Association. Circulation 102, 2284-2299.

48. Kris-Etherton P, Daniels SR, Eckel RH, et al. (2001) AHA Scientific Statement: Summary of the Scientific Conference on Dietary Fatty Acids and Cardiovascular Health. J Nutr 131, 1322-1326.

49. Hu FB \& Willet W (2002) Optimal Diets for Prevention of Coronary Heart Disease. JAMA 288, 2569-2578.

50. Wahrburg U (2004) What are the health effects of fat? Eur J Nutr 43, Suppl. 1, I/6-I/11.

51. Gebauer SK, Psota TL, Harris WS, et al. (2006) n-3 Fatty acid dietary recommendations and food sources to achieve essentiality and cardiovascular benefits. Am J Clin Nutr 83, Suppl, 1526S-1535S.

52. Kok FJ \& Kromhout D (2004) Atherosclerosis. Epidemiological studies on the health effects of a Mediterranean diet. Eur J Nutr 43, Suppl 1, I/2-I/5.

53. Wahlqvist ML (2005) Dietary fat and the prevention of chronic disease. Asia Pac J Clin Nutr 14, 313-318.

54. German D (2004) Saturated fats: what dietary intake? Am J Clin Nutr 80, 550-559.

55. Mann JI (2002) Diet and risk of coronary heart disease and type 2 diabetes. Lancet 360, 783-789.

56. Mensink RP, Zock PL, Kester AD, et al. (2003) Effects of dietary fatty acids and carbohydrates on the ratio of serum total to HDL cholesterol and on serum lipids and apolipoproteins: a meta-analysis of 60 controlled trials. Am J Clin Nutr 77, 1146-1155.

57. Sacks FM \& Katan M (2002) Randomized clinical trials on the effects of dietary fat and carbohydrate on plasma lipoproteins and cardiovascular disease. Am J Med 11, Suppl 9B, 13S-24S.

58. Jakobsen MU, O'Reilly EJ, Heitmann BL, et al. (2009) Major types of dietary fat and risk of coronary heart disease: a pooled analysis of 11 cohort studies. Am J Clin Nutr 89, 1425-1432.

59. Skeaff CM \& Miller J (2009) Dietary fat and coronary heart disease: summary of evidence from prospective cohort and randomized controlled trials. Ann Nutr Metab $\mathbf{5 5}$, $173-201$. 
60. Mozaffarian D (2005) Does alpha-linolenic acid intake reduce the risk of coronary heart disease? A review of the evidence. Altern Ther Health Med 11, 24-30, quiz 31, 79.

61. Mozaffarian D \& Rimm EB (2006) Fish intake, contaminants, and human health: evaluating the risks and the benefits. JAMA 296, 1885-1899.

62. Akabas SR \& Deckelbaum RJ (2006) Summary of a workshop on $n \_3$ fatty acids: current status of recommendations and future directions. Am J Clin Nutr 83, Suppl, 1536S-1538S

63. Connor WE (2000) Importance of $n-3$ fatty acids in health and disease. Am J Clin Nutr 71, Suppl, 171S-175S.

64. Harris WS, Mozaffarian D, Lefevre M, et al. (2009) Towards Establishing Dietary Reference Intakes for Eicosapentaenoic and Docosahexaenoic Acids. J Nutr 139, 804S-819S

65. Hooper L, Thompson RL, Harrison RA, et al. (2006) Risk and benefits of omega 3 fats for mortality, cardiovascular disease, and cancer: a systematic review. BMJ (Epub ahead of print; doi:10·1136/bmj.38755.366331-2F).

66. Horrocks LA \& Yeo YK (1999) Health benefits of Docosahexaenoic acid (DHA). Pharmacol Res 40, 211-225.

67. Simopoulos AP (1999) Essential fatty acids in health and chronic disease. Am J Clin Nutr 70, Suppl, 560S-569S.

68. Simopoulos AP (2001) n-3 Fatty Acids and Human Health: Defining Strategies for Public Policy. Lipids 36, S83-S89.

69. GISSI-HF Investigators (2008) Effect of $n-3$ polyunsaturated fatty acids in patients with chronic heart failure (the GISSIHF trial): a randomised, double-blind, placebo-controlled trial. Lancet 372, 1223-1230.

70. Brenna JT (2009) Background Paper on Fat and Fatty Acid Requirements during Pregnancy and Lactation. Ann Nutr Metab 55, 97-122.

71. Koletzko B, Cetin I \& Brenna JT, For the Perinatal Lipid Intake Working Group C (2007) Consensus Statement. Dietary fat intakes for pregnant and lactating women. $\mathrm{Br} J$ Nutr 98, 873-877.

72. Koletzko B, Uauy R, Palou A, et al. (2010) Dietary intake of eicosapentaenoic acid (EPA) and docosahexaenoic acid (DHA) in children - a workshop report. Br J Nutr 103, 923-928.

73. Lapillonne A \& Jensen CL (2009) Reevaluation of the DHA requirement for the premature infant. Prostaglandins Leukot Essent Fatty Acids 81, 143-150.

74. Le H, Meisel JA, deMeijer VE, et al. (2009) The essentiality of arachidonic acid and docosahexaenoic acid. Prostaglandins Leukot Essent Fatty Acids 81, 165-170.

75. Makrides M (2009) Is there a dietary requirement for DHA in pregnancy? Prostaglandins Leukot Essent Fatty Acids 81, 171-174.

76. Prentice A, Branca F, Decsi T, et al. (2004) Energy and nutrient dietary reference values for children in Europe: methodological approaches and current nutritional recommendations. Br J Nutr 92, Suppl. 2, S83-S146.

77. Uauy R \& Dangour AD (2009) Fat and Fatty Acid Requirements and Recommendations for Infants of 0-2 Years and Children of 2-18 Years. Ann Nutr Metab 55, 76-96.

78. Gil-Campos M, Dalmau-Serra J Comite de Nutricion Asociacion Española de Pediatria (2010) Importancia del ácido docosahexaenoico (DHA): funciones y recomendaciones para su ingesta en la infancia. An Pediatr (Barc) 73, $142 \mathrm{e} 1-142 \mathrm{e} 8$

79. Wolfram G (Ed.) (2005) The Nutrition Report 2004. Summary. Bonn: German Nutrition Society/Deutsche Gesellschaft für Ernährung e.V.

80. Czernichow S, Thomas D \& Bruckert E (2010) n-6 Fatty acids and cardiovascular health: a review of the evidence for dietary intake recommendations. $B r J$ Nutr $\mathbf{1 0 4}$ 788-796.

81. Ramsden CE, Hibbeln JR, Majchrzak SF, et al. (2010) n-6 Fatty acid-specific and mixed polyunsaturate dietary interventions have different effects on CHD risk: a meta-analysis of randomized controlled trials. Br J Nutr 104, 1586-1600.

82. Calder PC \& Deckelbaum RJ (2011) Harmful, harmless or helpful? The n-6 fatty acid debate goes on. Curr Opin Clin Nutr Metab Care 14, 113-114.

83. Deckelbaum RJ \& Calder PC (2010) Dietary n-3 and n-6 fatty acids: are there 'bad' polyunsaturated fatty acids? Curr Opin Clin Nutr Metab Care 13, 123-124.

84. Molendi-Coste O, Legry V \& Leclercq IA (2011) Why and How Meet n-3 PUFA Dietary Recommendations? Gastroenterol Res Pract, 2011,364040 (Epub December 8, 2010).

85. Kris-Etherton PM, Grieger JA \& Etherton TD (2009) Dietary reference intakes for DHA and EPA. Prostaglandins, Leukot Essent Fatty Acids 81, 99-104.

86. Wang C, Harris WS, Chung Mn-3, et al. (2006) Fatty acids from fish or fish-oil supplements, but not alpha-linolenic acid, benefit cardiovascular disease outcomes in primaryand secondary-prevention studies: a systematic review. Am J Clin Nutr 84, 5-17.

87. Ness AR, Hughes J, Elwood PC, et al. (2002) The long-term effect of dietary advice in men with coronary disease: follow-up of the Diet and Reinfarction Trial (DART). Eur J Clin Nutr 56, 512-518.

88. Yokoyama M, Origasa H, Matsuzaki M, et al. (2007) Effects of eicosapentaenoic acid on major coronary events in hypercholesterolaemic patients (JELIS): a randomised open-label, blinded endpoint analysis. Lancet 369, 1090-1098.

89. Marik PE \& Varon J (2009) Omega-3 Dietary Supplements and the Risk of Cardiovascular Events: A Systematic Review. Clin. Cardiol 32, 7, 365-372.

90. Burr ML, Dunstan FDJ \& George CH (2005) Is Fish Oil Good or Bad for Heart Disease? Two Trials with Apparently Conflicting Results. J. Membrane Biol. 206, 155-163.

91. Rauch B, Schiele R, Schneider S, et al. (2010) OMEGA, a randomized, placebo-controlled trial to test the effect of highly purified omega-3 fatty acids on top of modern guideline-adjusted therapy after myocardial infarction. Circulation 122, 21, 2152-9 (Epub November 8, 2010).

92. Kromhout D, Giltay EJ \& Geleijnse JMfor the Alpha Omega Trial Group (2010) n-3 Fatty Acids and Cardiovascular Events after Myocardial Infarction. $N$ Engl $J$ Med 363, 2015-2026.

93. Filion KB, El Khoury F, Bielinski M, et al. (2010) Omega- 3 fatty acids in high-risk cardiovascular patients: a metaanalysis of randomized controlled trials. BMC Cardiovasc Disord 10, 24.

94. Nodari S, Triggiani M, Campia U, et al. (2011) n-3 Polyunsaturated fatty acids in the prevention of atrial fibrillation recurrences after electrical cardioversion. A prospective, randomized study. Circulation 124, 1100-6 (Epub August 15, 2011).

95. Liu T, Korantzopoulos P, Shehata M, et al. (2011) Prevention of atrial fibrillation with omega-3 fatty acids: a meta-analysis of randomised clinical trials. Heart 97, 13, 1034-1040 doi:10.1136/hrt.2010.215350 (Epub April 8, 2011).

96. Crawford MA, Bazinet RP \& Sinclair AJ (2009) Fat intake and CNS functioning: ageing and disease. Ann Nutr Metab 55, 202-228.

97. Kornsteiner M, Singer I \& Elmadfa I (2008) Very low n-3 long-chain polyunsaturated fatty acid status in Austrian vegetarians and vegans. Ann Nutr Metab 52, 37-47. 
98. Joint FAO/WHO Expert Consultation on the Risks and Benefits of Fish Consumption. 25-29 January 2010, Rome, Italy. Available at URL: (ftp://ftp.fao.org/FI/DOCUMENT/ risk_consumption/executive_summary.pdf) (accessed May 2011).

99. Food and Drug Administration, Environmental Protection Agency (2004) What you need to know about mercury in fish and shellfish. Washington, DC, (EPA-823-R-04-005).

100. Wijendran V \& Hayes KC (2004) Dietary n-6 and n-3 fatty acid balance and cardiovascular health. Annu Rev Nutr 24, 597-615.

101. Burdge GC \& Calder PC (2006) Dietary a-linolenic acid and health-related outcomes: a metabolic perspective. Nutr Res Rev 19, 26-52.

102. Hibbeln JR \& Davis JM (2009) Considerations regarding neuropsychiatric nutritional requirements for intakes of omega-3 highly unsaturated fatty acids. Prostaglandins, Leukot Essent Fatty Acids 81, 179-186.

103. Willett WC (2007) The role of dietary n-6 fatty acids in the prevention of cardiovascular disease. J Cardiovasc Med (Hagerstown) 8, Suppl. 1, S42-S45.

104. Calder PA (2010) The American Heart Association advisory on $\mathrm{n}-6$ fatty acids: evidence based or biased evidence? $\mathrm{BrJ}$ Nutr 104, 1575-1576

105. Mozaffarian D \& Willett WC (2007) Trans fatty acids and cardiovascular risk: a unique cardiometabolic imprint? Curr Atheroscler Rep 9, 486-493.
106. Mozaffarian D \& Clarke R (2009) Quantitative effects on cardiovascular risk factors and coronary heart disease risk of replacing partially hydrogenated vegetable oils with other fats and oils. Eur J Clin Nutr 63, 522-533.

107. Ascherio A \& Willet W (1997) Health effects of trans fatty acids. Am J Clin Nutr 66, Suppl, 1006S-1010S.

108. Eckel RH (2007) Understanding the Complexity of Trans Fatty Acid Reduction in the American Diet: American Heart Association Trans Fat Conference 2006: Report of the Trans Fat Conference Planning Group. Circulation 115, 2231-2246.

109. Marcanson W (2006) How Many Grams of Trans-Fat Are Recommended per Day? J Am Diet Assoc 106, 1507.

110. Fernandez ML \& Calle M (2010) Revisiting Dietary Cholesterol Recommendations: Does the Evidence Support a Limit of $300 \mathrm{mg} / \mathrm{d}$ ? Curr Atheroscler Rep 12, $377-383$

111. WCRF/AICR. Expert report: Continous update project. Available at URL (http://www.wcrf.org/cancer_research/ cup/index.php) (Accessed May 2011).

112. WHO Nutrition Guidance Expert Advisory Group (NUGAG). Available at URL: (http://www.who.int/nutrition/topics/ NUGAG_subgroup_micronutrient_dietandhealth/en/index. html) (accessed May 2011) 